\title{
LA REVISION CRÍTICA DE CARLOS RINCÓN
}

\author{
Por \\ IVAN URIARTE \\ University of Pittsburgh
}

No es posible, en el límite de una nota, dar cuenta de la importancia y consecuencias de un libro como El cambio en la noción de literatura ${ }^{1} \mathrm{del}$ colombiano Carlos Rincón, estudioso formado en la escuela alemana de la Rezeptionästhetik e influido por el revisionismo marxista. Rincón inscribe este conjunto de proposiciones dentro de una crítica de revisión total "del aparataje categorial empleado hasta hace muy poco en las que aparecían como la crítica y la historiografía dominantes", como afirmó en un ensayo sobre "La actualidad de la vanguardia", publicado durante su estancia en Cuba y ausente de este volumen. Desde tal perspectiva se pasa revista y se cuestionan las teorías y métodos empleados por las críticas del idealismo inmanentista, como el formalismo ruso, el estructuralismo checo y su proyección francesa y americana, el "New criticism" de Norteamérica, la lingüística del texto, etc. Rincón nos da una visión dialéctica de la crisis y cambio en la dirección crítica latinoamericana actual, en un período que va de la Revolución Cubana a las vísperas de la más reciente de Nicaragua, donde ahora se encuentra trabajando. Aspira a ser un examen abarcador que analiza libros, monografías, tesis doctorales, ponencias de congresos, estudios y artículos, notas, reseñas de revistas académicas y periódicos literarios o corrientes. En este vasto proyecto el Brasil no queda marginado, como ha ocurrido a menudo, sino integrado a la totalidad literaria del continente. $\mathrm{Y}$, además, no se crea que sólo el idealismo inmanentista es cuestionado, sino también cierta crítica sociologizante que ha tenido divulgación en Latinoamérica, como la derivada de Lukács, Goldmann o la de un marxismo que no supera la ortodoxia, como en el caso de Adolfo Sánchez Vázquez, teorizante español radicado en México. Grosso modo, la tesis central que vertebra la revisión de Rincón es la siguiente: la crítica latinoamericana ha estado dominada por un idealismo inmanentista, a-historicista, formal, producto de los "ideologemas surgidos

1 Carlos Rincón, El cambio en la noción de literatura. (Bogotá: Instituto Colombiano de Cultura. Colección Autores Naciónales, 1978). 
en la sociedad europea occidental desde el siglo XIX como respuesta a la racionalidad burguesa". Para Rincón, esta crítica es incapaz de enfrentarse a la nueva producción literaria que es resultado del cambio social que está ocurriendo hoy en el mundo, y en su impotencia se parapeta en la supuesta objetividad epistemológica de sistemas como los del actual estructuralismo o la semiología que niega a los referentes.

¿Cuáles son - según Rincón- las razones por las cuales esta crítica estuvo y sigue estando incapacitada para enfrentarse al cambio? Los límites de esa crítica residen; ya sea el formalismo crítico de Enrique Anderson Imbert, la estilística de Amado Alonso, la forma de recepción del estructuralismo de Octavio Paz o el "New criticism" de Afrânio Coutinho, entre otros, en el hecho de no poder resolver "la problemática de las relaciones entre producción y recepción, vistas como proceso autónomo". Así, por ejemplo, "la actualidad de la vanguardia" exige a la investigación actual "dar cuenta de manera simultánea de la unidad y el carácter contradictorio del hecho literario perteneciente al pasado, su actual imagen y su acción sobre la conciencia de nuestros contemporáneos". Y es por ello que la crítica ha permanecido sin captar "las relaciones que mantiene con la vanguardia" un grupo de autores tan diversos como García Márquez, Ernesto Cardenal y Octavio Paz. Una crítica preocupada por la producción literaria como algo hecho esencialmente de lenguaje (recuérdese a propósito del "boom", la explosiva tesis de Rodríguez Monegal de que el verdadero personaje de la literatura latinoamericana es el lenguaje), no puede confrontar una literatura "en su cambiante proceso de producción y recepción, como una forma estética de praxis social". Ese cambio de la función de la literatura, además, no reside ni en la nueva novela, ni en la poesía, ya sea el exteriorismo o la antipoesía; se trata de un cambio que se ha venido operando en la noción de literatura, confirmado, además, por dos síntomas: "el peso particular que ha venido a tomar un género propio de nuestras literaturas, como es el cuento o el conto" y la renovada actualidad de la vanguardia. Es un cambio ocasionado por la "presión del proceso social en el continente, que ha llevado, a nivel ideológico, no sólo a hacer saltar los marcos sino a poner en cuestión la realidad misma de una esencia sustancialista de la literatura". Esa nueva función y puesto de la literatura se ha dado también ante "la prueba a que la sometieron obras que a la vez que exigen una nueva relación con el lector" nos muestran que "el texto literario no es exclusivamente aquél cuyo objeto resulta constituido sólo en $/ y$ a través del lenguaje y que la literatura no es una producción de ficciones sino de efectos específicos".

Antes de precisar las obras que exigen esa nueva relación con el lector, señalemos de qué manera el problema de la recepción de la lectura impide 
al estructuralismo, y a las diversas versiones del idealismo crítico, enfrentarse al problema del cambio. Para Rincón, Octavio Paz, uno de los primeros en ocuparse del problema de la lectura en nuestro medio - a mediados de los sesenta - ejemplifica bien los límites del planteamiento estructuralista, el cual acogió apresuradamente según el crítico colombiano, antes de dejar el existencialismo de El laberinto de la soledad. Dos cuestiones de importancia señala Rincón a propósito de la concepción teórico-literaria del ensayista mexicano: "las relativas a las dicotomías de estructura-recepción y obra cerrada-abierta". Paz, en el conocido ensayo "Tradición y ruptura", se preguntaba si el carácter artístico de la obra dependía de su estructura, prefijando ya su recepción, o si dependía del proceso mismo de recepción, dándole desde ese momento la propiedad particular de realizar una percepción estética de la obra. En ambas, sostiene Rincón, Paz se sitúa al margen del carácter histórico del hecho literario, impidiendo llegar al establecimiento de la relación no normativa que existe entre texto y recepción, lo cual, por eso, no determinó teóricamente los diversos niveles del efecto literario ni pudo "abarcar sus muy variados aspectos históricos y estéticos". Así, pues, Paz no se ocupó del problema estructura-recepción. "Se limitó sólo a plantear esa dicotomía y a remitirla a otras dos oposiciones: tradición-ruptura, y referida al estudio de Eco sobre Opera aperta (1962), la que se daría entre "obra abierta" y "obra cerrada". El examen de Rincón sobre la posición de Paz concluye "que los términos de esta última posición van a regir una serie de especificaciones: obra cerrada, cuya comprensión supondría la recepción de un mensaje; obra abierta, cuya lectura exigiría un trabajo de desciframiento". Para Rincón, "bajo sus exteriores estructuralistas la tipología que aspira a elaborar Paz no sólo falsea lo que ha sido el desarrollo históricoliterario del fenómeno de la lectura...", sino que incluso reduce "a la transformación del tipo de obra producida" el programa revolucionariocultural de la vanguardia.

Después de juzgar como un "juego preterido de enmascaramientos y desfases" las poéticas surgidas en la década de los sesenta ("momento de decisiones ideológicas, artísticas y políticas") como el realismo mágico de Asturias, lo fantástico de Borges, o la simultaneización del lector de Cortázar, Rincón concluye que el tipo de obra que registra el cambio es $E l$ cimarrón (1967), del cubano Miguel Barnet. El cimarrón es un relato autobiográfico en el cual "la individualidad que preside la organización del monólogo...es distinta del yo que narra su existencia". Ahora bien, "el impulso para la escritura del texto proviene de intereses de orden político e historiográfico que no se confunden inmediatamente con el Yo de la realidad autobiográfica narrada, presente en el libro". Frente a obras 
(marcadas por el Yo), como en Martereau, por ejemplo, El cimarrón sobresale por un gran arte narrativo que en vez de recrear una apariencia de la vida "consigue restituir la vida, en su multiplicidad misma, producida por una persona concreta, identificada, sin que el autor y el lector se engañen al respecto". Además, en su praxis literaria El cimarrón se libró de la coerción normativa y desechando "el material tradicional y los medios y objetivos correspondientes recurrió a la materia no ficticia". Esto echa por tierra aquello de que el texto literario narrativo tiene validez sólo a partir de la ilusión, o de la apariencia de la vida, o de la preocupación por suscitarlas.

El cambio en la noción de literatura, pues, hace saltar el casillero de los géneros "paralelo a la canonización de literatura y no literatura dentro de la ideología literaria burguesa". Esa forma documental que adopta la obra de Barnet es para Rincón un peso engendrado por la afluencia de realidades históricas, sociológicas, políticas que escaparon a los métodos y formas disponibles para su tratamiento, "lo cual especifica un aspecto central de su actual función". Esta obra, por otra parte, no se emparenta con otras literaturas documentales que van de Brecht a Truman Capote o el antropólogo Oscar Lewis, porque lo nuevo en ella es que apunta "al análisis concreto de nuestro proceso histórico-social y a las relaciones que mantiene con él nuestra producción literaria". A eso hay que agregar una observación fundamental: "el relato autobiográfico y biográfico real, y más recientemente ficticio, constituyen en nuestros países la línea básica de proceso cumplido a lo largo de cuatro siglos", que van de las Relaciones a Concolorcorvo, incluyendo el descubrimiento reciente del excepcional Poma de Ayala; del nivel ficticio de Memorias de un sargento de milicias, de Manuel Antonio de Almeida o las Memorias póstumas de Braz Cubas, hasta la novela de la Revolución Mexicana y el guayanés africano de lengua francesa, René Maran. La gestación de la novela, concluye al respecto Rincón, alcanzará su fin "con la llegada de la producción que nos es contemporánea". Y así, "dentro del proceso revolucionario en que se halla inscrita nuestra sociedad, surge ese tipo de autobiografía que constituye El cimarrón".

Sin embargo, los primeros precedentes o "síntomas" del fenómeno los encuentra Rincón en obras diversas que traslucen "cambios en la autocomprensión de los poetas, escritores de teatro y prosistas", tales como Soleil de la conscience (1956), Guerra sem testamunhas (1969), Pobrecito poeta que era yo (1976), la obra póstuma de Roque Dalton. Señala también, cómo a lo largo de los cincuenta y los sesenta hay, como cumplimiento de tendencias básicas, una "reelaboración del lenguaje de la narrativa" realizado desde la poesía de Cardenal; a esto puede agregarse la 
promoción de "formas operativas", en particular la canción, que abarca hacia los años sesenta países como Chile, la Argentina y el Uruguay. Ellos forman parte de una poesía que también registra la conciencia del cambio: Violeta Parra, "uno de los poetas latinoamericanos más grandes de este siglo", Víctor Jara, Chico Buarque de Holanda y otros que Rincón no cita como: Atahualpa Yupanqui ("Preguntitas a Dios" es la primera canción que cuestiona la buena conciencia de las oligarquías latinoamericanas, la burguesía y el imperialismo), Carlos Mejía Godoy, David Vigliety, etc.

Ese fenómeno del cambio, continúa Rincón, se complementa con un género en el que puede constatarse - a través de la crítica que ha dedicado especial atención tales como la de Mario Lancelotti, Julio Durán Cerda, Lida Aronne Amestoy o en la latinoamericanística norteamericana, la recopilación de Pupo Walker, El cuento hispanoamericano ante la critica-"una práctica que fracasa ante el problema del género como categoría y la historia de la literatura como proceso". Frente a la short story americana -que significa haberse llegado a imponer en el mercado- el cuento latinoamericano, a semejanza del racconto, de la Kurgeschichte, como la lírica, tiene requisitos propiamente literarios, asentados en "rasgos característicos de una fase social preindustrial". Además, el cuento "tiene una función de iniciación literaria para escritores y lectores". Ahora bien: la práctica de la prosa narrativa corta, se trate de Rulfo, Guimaraes Rosa o Skármeta, demuestra en oposición a Borges, que esa forma se elige por falta de lo que llama 'el optimismo del siglo XIX', y las conocidas falacias contra la novela para justificar su lucidez de hacer caber el mundo "en una nuez de quince minutos", indica que la "forma genérica no se elige, la forma se impone y de alli toda una serie de hechos paradójicos", resumibles asi: la primera paradoja sería la "voluntad de restablecer en forma particular" una perdida situación existente (el proceso real de contar un cuento), estatuyéndose una relación especial entre texto y lector, que por su brevedad y unidad de tiempo tiene semejanzas a lo experimentado con la parábola o la lírica. Segunda paradoja: "la situación del texto en campos intermedios", de lo cual surgen posibilidades sin fin: "narración abierta y exploratoria con final cerrado, narración abierta desplegada con terreno medianero con final abierto, narración cerrada con final abierto, etc.". La tercera paradoja - la fundamental para Rincón - es "el peso decisivo de la materia", que es lo que cuenta sobre todo lo demás, y, sin embargo, la importancia poética reside sólo desde el ángulo en que el lector se sitúe.

Después de considerar el cuento como "el verdadero laboratorio de la narración en Latinoamérica", Rincón observa que, contrariamente a la doctrina clásica consolidada dentro de la estética burguesa ("la teoría debe marchar a la zaga de la producción"), al "invertirse en Latinoamérica la 
relación tradicional entre norma estética y praxis literaria, los productores comenzaron a intentar producir su propia teoria", que parte del "Decálogo del perfecto cuentista" de Quiroga y, pasando por Guimaraes Rosa y Bosch, concluye con "Del cuento breve y sus alrededores" de Cortázar. Así, pues, la función propia del cuento abre las posibilidades de un diálogo entre la teoría y la práctica, que incidiría en el desarrollo de "nuestras modalidades de lectura y escritura, dentro del proceso de redefinición de la noción de la literatura".

Esta es, grosso modo, la tesis central que circula en este conjunto de ensayos, que proponen, además, desde una posición política de clase, la redefinición "del campo de objetos de la investigación histórico-literaria". Para finalizar, más que dar cuenta de la vasta información que despliega este libro "fourmillant" de nombres y citas y donde el cuestionamiento a la luz de una crítica materialista de la literatura incluye los autores más diversos, que van del formalismo crítico de Anderson-Imbert hasta las sutiles "máscaras" y "transparencias" de Octavio Paz, Rolland Barthes o Afrânio Coutinho, nos queda por lo menos dar una somera idea de cada uno de los ensayos restantes. (Nuestra reseña se ha centrado alrededor del primer ensayo: "El cambio actual de la noción de literatura en Latinoamérica"). El ensayo siguiente se titula "El crítico, ¿un estratega de las luchas literarias?". En cuarenta páginas Rincón examina la función del crítico en América Latina, detectado en su nacimiento, durante el romanticismo, y centrándose en la problemática principal de que no "sólo el hecho literario posee historicidad propia, sino también los criterios y valoraciones estético sociales"(56). Examina el binomio historia de la literatura y crítica literaria, la crítica como ensayo, la literatura como ciencia, la estilística, la sociología de la literatura, el problema de la recepción, siguiendo aquí la tesis de Jauss y Manfred Nauman. Para Rincón el ensayo latinoamericano de hoy viene a ser un instrumento fundamental, pues, no obstante su inconsistencia, llama la atención su ironía interna. Hay en nuestro crítico (Benedetti es un buen ejemplo) una vocación secreta - que no es la desinteresada transcripción de intuiciones e impresiones de lectura - sino la de querer devenir "un estratega de las luchas literarias, tal como Benjamin - un modelo de crítico para Rincónlo quería en la primera de las "Trece reglas del crítico".

El tercer ensayo, "Nueva producción y crisis de la crítica tradicional", tiene por fin demostrar el "desconcierto" de la crítica latinoamericana dominante - a mediados de los cincuenta - al confrontar "bajo nuevas condiciones sociales una nueva producción". En el campo de la novela Rincón señala el desconcierto frente a obras como El reino de este mundo, Hombres de maiz, Grande Sertão: Veredas o La hojarasca. Ese 
desconcierto se debió, esencialmente según el crítico, al desconocimiento de la relevancia histórica y política para la teoría y la práctica de la novela. Al reducir al aspecto puramente técnico-narrativo el problema de la novela, se eliminaban "cuestiones relativas al efecto y a la recepción, y con ello a la función de la literatura y la novela en nuestras sociedades". En el campo de la lírica, esta crítica, encerrada en el formalismo, tropezó con la antipoesía y la poesía conversacional, la que al acoger el verso libre y el prosaismo, chocaba "con las hipótesis analíticas de Jakobson sobre las funciones del paralelismo morfológico lexemático y sintáctico". Para el concretismo del Brasil señala cómo "el lenguaje poético tendió a definirse ya en el sentido de una forma de producción linguística".

"Acerca de la 'nueva crítica latinoamericana'. Posiciones y problemas" es el cuarto ensayo del libro. Aquí se cuestiona "el camuflaje de la crítica tradicional" al querer hacer aparecer su fracaso frente a la nueva producción como "una crisis de los métodos de abordaje del hecho literario"; con lo cual se trataba de ocultar las implicaciones políticas. Así, esta "nueva crítica latinoamericana" (nueva, entre comillas, desde luego) aparece emparentada con la recepción de la línea sellada por la linguística (el formalismo ruso, el estructuralismo checo, el reciente estructuralismo francés en sus diversas versiones, y últimamente el New criticism). Lo que verdaderamente rompe la serie de interrogaciones inmanentistaestructuralistas de esta crítica, son las diversas lecturas de un texto. Son notables aquí los nexos que Rincón encuentra entre La leyenda del lugar florido de Asturias y Salambó de Flaubert. En este ensayo Rincón reconoce a Carpentier como un pionero de la crítica latinoamericana, dado que fue el primero (1935) en plantear la cuestión de la recepción y el efecto de la literatura "no sólo a partir de la consideración obra-lector". Después de cuestionar el "Nouveau roman" y la "Nouvelle critique" francesa, a propósito de la revisión de la sucesiva lectura de varios textos, entre otros el estudio sobre Martín Rivas de Jaime Concha, el autor parece darnos su posición: "la producción literaria no puede ser interrogada exclusivamente desde el punto de vista de la objetivación y la representación. . . Debe serlo ante todo como forma de práctica social, como fuerza que configura la Historia".

El quinto ensayo, "Sobre la transformación del campo, de la crítica y la didáctica: la llamada subliteratura", trata de un nuevo campo de estudios de la crítica latinoamericana, la llamada subliteratura, que ha agudizado el hecho literario en tanto que fenómeno histórico-social "que no existe fuera de su efecto y recepción". "Cabría decir inclusive, agrega Rincón, que ha implicado de hecho una revisión de la noción literatura". Partiendo de la expresión "industria cultuṛal", acuñada por la Escuela de Franckfurt, el 
crítico colombiano aborda el fenómeno de la "literatura de masas", literatura kisch, "literatura popular" y su importancia ideológica como "estrategia de la dominación cultural imperante". Considera que surge a un nivel "de desarrollo tecnológico, importada, acorde con el nivel propio alcanzado por el proceso del capitalismo dependiente latinoamericano, desde la fase inmediatamente precedente a la actual, la de la llamada substitución de importaciones". Ha dado lugar, pues, a "una proliferación de formas épico-visuales (fotonovelas, historietas), dramáticas (radionovelas, seriales de TV) y líricas (baladas, canciones), al lado de materiales novelescos producidos industrialmente, por varios redactores a la vez, que irían desde Corín Tellado hasta el ingenioso Marcial Lafuente Estefanía (que extrañamente Rincón no cita). También estudia las relaciones establecidas de algunos nuevos novelistas con la subliteratura, tales como García Márquez, Vargas Llosa, Puig. El problema de la recepción de este tipo de obras es estudiado ampliamente, así como una convergencia entre obra y recepción, y entre obra y destinatario: la tesis es que la obra cumple "una función ajustada a la ideología dominante", o sea, que se crea una relación concreta entre el texto y el lector, "o la imagen y el sonido con el receptor, dentro de una situación de comunicación ideológico-social determinada". Otros problemas, tales como la función de la enseñanza y de la literatura, son abordados.

El ensayo final, "Hacia una teoría de la literatura latinoamericana. Fundamentaciones y perspectivas", tiene un intención básica: no sólo la de dar cuenta de los distintos debates literarios (clausurados a nivel continental por la militarización de los años 60-63), sino también "determinar la validez de los enfoques teóricos que presidieron la conceptualización de fenómenos que han estado en relación con procesos incluidos en este clausurado ciclo, y avanzar hacia nuevas categorizaciones para dar cuenta de una transformada realidad". Rincón reduce a dos los caminos principales de la crítica en el campo de la teoría de la literatura: a) una que "articula el proceso literario al proceso social" (Alejandro Losada) y que trata de constituir una crítica y una historiografía no sometidas a ningún colonialismo cultural (Roberto Fernández Retamar). Con ella "la consideración de la teoría y la práctica en el proceso histórico literario latinoamericano se abrió hacia una interrogación sobre la función social de la literatura y sus transformaciones. Este punto es el centro de la problemática contemporánea en materia de teoría literaria en general. b) aparece el segundo camino esencialmente preocupado por el aspecto linguístico de la obra literaria, marcada por el reduccionismo al cual ya hemos aludido. 
Rincón, después de señalar los primeros intentos de Roberto Fernández Retamar (en "Por una teoría de la literatura hispanoamericana"), reconoce que búsquedas como éstas, y como las de Françoise Perus y Alejandro Losada, rebasan la herencia idealista que tiende "a cosificar la teoría de la literatura". También se ocupa Rincón ampliamente de la crítica brasileira y señala, a propósito de la "deshistorización cumplida por una analítica formal inmanentista, las consecuencias de superar una crítica impresionista que lleva a crear un cortocircuito metodológico" como es el de "referir directamente autor y obra". De esa manera queda velado cómo, "al determinarse el objeto de conocimiento teórico-literario", se toma una posición, no solamente dentro de la historia de las teorías o métodos literarios, sino más bien a nivel político. Es imposible dar cuenta de todos los puntos controvertidos tanto en éste como en los otros ensayos; digamos solamente que - para Rincón - el concepto de literaturnost de Jakobson aparece como la fórmula deshistorizante del formalismo y por ende de la "nueva crítica latinoamericana", y al igual que la teoría de Warren y Wellek, por citar un texto muy difundido en Occidente, así como el concepto de escritura de Roland Barthes, deben ser rechazados. En conclusión, podemos afirmar que este conjunto de ensayos es un ambicioso trabajo de revisión crítica, el primero entre nosotros que intenta una sistematización adecuada para cuestionar a fondo la crítica tradicional y la llamada "nueva crítica latinoamericana". Desde luego que no es un trabajo que aparece en el vacío. La estrategia de una nueva crítica marxista comenzó a definirse con trabajos como los de Portuondo, Fernández Retamar, Agustín Cuevas, Mejía Duque, Ariel Dorfman, Alejandro Losada, Françoise Perus y Hernán Vidal entre otros. No es mi intención juzgar esta crítica, por otra parte, alejada de cualquier ortodoxia y fundamentalmente preocupada por situar su estrategia crítica, desde una posición de clase. Sólo así se explica esta tentativa de redefinir la noción de literatura y de invertir los valores de la "crítica burguesa", así denominada por un difundido libro de Friedlender. 
